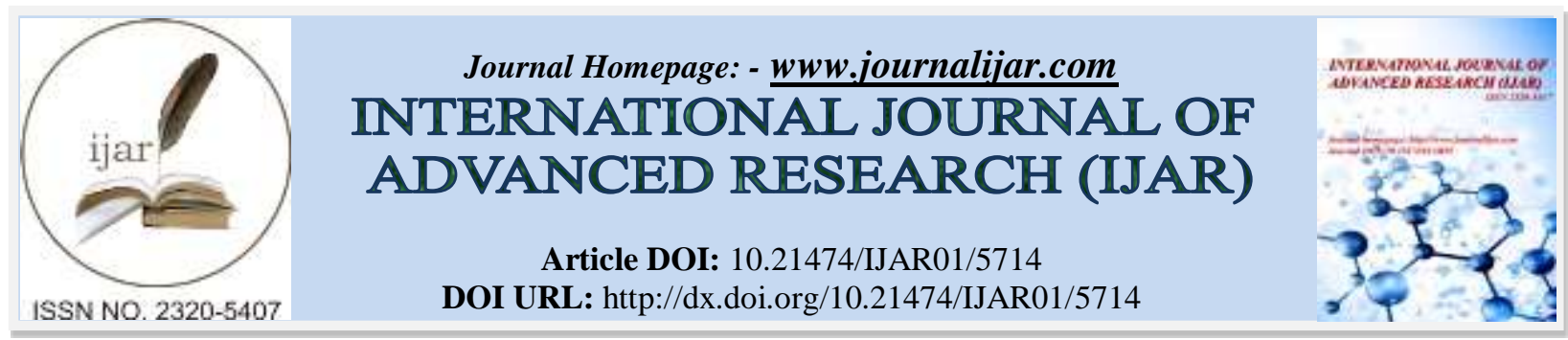

RESEARCH ARTICLE

\title{
FEED FORMULATION OF WILD GAUR BASED ON THE GROSS STRUCTURE AND HISTOMORPHOLOGY OF FORESTOMACH.
}

\author{
V. R. Annie ${ }^{1}$, Shruti ${ }^{2}$, Sunilkumar Patil ${ }^{3}$, K. V. Jamuna ${ }^{4}$ and ${ }^{*}$ V. Ramkrishna ${ }^{5}$. \\ 1. PhD. Scholar, Department of Veterinary Anatomy and Histology, COVAS, Mannuthy, Thrissur, Kerala. \\ 2. MVSc. Scholar, Department of Veterinary Anatomy and Histology, Veterinary College, Bangalore. \\ 3. PhD. Scholar, Department of Veterinary Anatomy and Histology, Veterinary College, Bangalore. \\ 4. Prof. \& Head, Department of Veterinary Anatomy and Histology, Veterinary College, Bangalore. \\ 5. Retd. Prof. Department of Veterinary Anatomy and Histology, Veterinary College, Bangalore.
}

\section{Manuscript Info}

\section{Manuscript History}

Received: 24 August 2017

Final Accepted: 26 September 2017

Published: October 2017

\section{Key words:-}

Wild Gaur, Forestomach, Gross morphology, Histology, Intermediate grazer.

\begin{abstract}
Ruminants have been clasiified as grazer, browser and intermediate type. The study was conducted on Wild Gaur to categorize the feed formulation based on the gross morphological and histological study of the forestomach.Tissue samples from forestomach were taken and observed under stereozoom microscope, later processed and blocked in paraffin wax for histomorphological studies. Histologically, forestomach was made up of stratified squamous keratinized epithelium. The ruminal papillae of the gaur were shorter and broader papillae. The primary crest or taller crest were quite big and were divided into smaller crest but were not distinct. The upper border of the taller crest showed pointed projected long conical papillae. In rumen, lamina muscularis mucosae was absent but found only in primary reticular crest of reticulum and was distinct in omassum. Based on these morphological parameters Wild Gaur can be classified as Intermediate type.
\end{abstract}

Copy Right, IJAR, 2017,. All rights reserved.

\section{Introduction:-}

Ruminants have been classified as grazer, browser and intermediate type. It has been established that the anatomical features of the forestomach of ruminants play a major role in providing nutrition for the animal behaviour, physiology, growth and reproduction. Formulating affordable and practical diet for wild ruminants have proved a challenging job for zoo/national park and wild life sanctuaries. Tradionally most of the diets were designed for wild ruminants as per the domestic ruminants that is cow, sheep, goat, buffalo. The presence of carbohydrate rich diet may be unsuitable for maintaining wild ruminants because these animals may be unable to absorb and metabolize the end product of fermentation that is volatile fatty acid at the rate of its production. Excess of acid in blood may lead to systemic acidosis or rumen acidosis. According to several authors, nutrition of wild ruminants in captivity still have more challenges. Hofmann and Stewart (1972) classified them into a flexible system of three overlapping morphophysiological feeding types: concentrate selectors, grass and roughage eaters and intermediate, opportunistic mixed feeders. Today "grass and roughage eaters" and particularly the contradictory term "concentrate selectors" were replaced by the terms "grazers" and "browsers" according to the natural forage of these ruminants (Clauss et al. 2003a). Knowing the morphophysiological adaptation of the ruminants and histomorphogical features with the gross features of forestomach still offer immense help for the nutritionist engaged in animals kept in captivity and in 
wild to formulate feeding schedule. Therefore to categorize the feeding type, the gross morphological and histological study of the forestomach of gaur has been undertaken in the present study.

\section{Materials and Methods:-}

The rumen, reticulum and omassum from gaur were collected during post-mortem. Further the rumen, reticulum and omassum were opened and the contents were removed by washing. The tissue sample of rumen from ventral sac was taken. Shape and surface of papillae were observed using stereozoom microscope. The sample of reticulum was taken from the centre of the reticulum. Surface view (shape) of reticular cell, shape and pattern of papillae on primary reticular crest were observed by using stereozoom microscope. Similarly sample of omassum was also taken and same above observations were recorded. Then tissue pieces of 3-5 mm length were fixed in 10 per cent neutral buffered formalin. The tissue pieces were routinely processed and blocked in paraffin wax. The sections of 7 $\mu \mathrm{m}$ thickness were stained for $\mathrm{H}$ and E, Masson's Trichrome, Verhoeff's elastic fiber, Gomori's reticulin and Bielschowski stain (Luna, 1968).

\section{Results and discussion:-}

\section{Rumen:-}

Gross morphology:-

Lakshmishree (2014) mentioned that ruminants which were more towards grazer type (black buck, nilgai and buffaloe) had shorter and thinner ruminal papillae where as in the ruminants with more towards browser type (spotted deer, sheep and goat) had longer and broader papillae. Similarly nilgai and buffalo papillae were closely related to the gaur but had shorter and broader papillae (Fig.1). Hofmann (1989) described that the grazers tend to have larger papillae, in rumen/reticulum than do browsers. The sequential changes from tongue or conical to spatula or leaf shape papillae may be due to forage type dependent grazer and browser ruminants, which was an area that showed large alteration in the absorptive surface of the papillae in relation to the feeding regimes as reported by Gabel et al. (1987). Hofmann (1989) stated that the browsers tend to have extensive dense papillae in all parts of the rumen, which may allow efficient absorption of VFA's from the rapidly fermenting cell contents of the browse plants. In contrast, grazers had fewer, uneven papillae that limit the absorptive capacity of the rumen. Although, papillae served as absorptive structures, the total ruminal volume and surface area had a significant influence on nutrient transport (James et al. 1983), so changes in papillary size indicate a marked increase of relative rumen epithelial absorptive surface. The intake of high levels of protein and carbohydrate appeared to increase papillary size and density via butyrate and propionate regulation of IGF-1 production in goat (Shen et al. 2004) and was partially due to SCFA dependent increase in the mitotic index of the rumen epithelium of calf. However, Lentle et al. (1996) reported that the quality of ingested food affects the size of rumen papillae in red deer.

\section{Histology:-}

In the present study lamina epithelia was made up of stratified squamous keratinized epithelium (Fig. 2, 3) as reported by Ramkrishna and Gadre (2004), Eurell \& Frappier (2006) and Lakshmishree (2014). 6-7 cell layer stratum corneum was seen in the present study of lamina epithelia. Lakshmishree (2014) reported minimum cell layer in black buck and buffalo and maximum in spotted deer, sheep and goat and also observed swollen large vacuoles containing lipid droplets in the epithelium. Similar vacuolated space surrounding the nuclei were also seen in the epithelial layers of gaur indicating the presence of lipids was observed (Fig.4). Rasha (2007) mentioned highest increase in the thickness of stratum corneum in the sheep due to concentrate diet. Hofmann and Schnoor (1982), considered the effect on the transport of nutrients to diet which could be due to higher degree of keratinisation and integrity of the cells. The vegetal food is necessary for the total development of the histological structure of the rumen. Different food can alter the appearance of the surface of mucosa of the rumen and can affect the histological structure of stratum granulosum and stratum corneum. Since grasses have a relatively high content of silica which explain the difference in the erosion of stratum corneum. This may provoke a greater friction among the particles of food and mucosa. The very low fibre content in the diet causes the incidence of parakeratosis in the animals which consumed more concentrate (Bull et al. 1965). Jones et al. (1972) mentioned that the large amount of silica (biogenic) may also influence the utilization of other nutrients. The concentration of volatile fatty acid depends on the production and absorption across the epithelium of different chamber (rumen) since it triggers an increase in the epithelial growth in the rumen (Dirksen et al. 1984). The other layers of the rumen were similar to the descriptions given by various histologists. Rasha (2007) reported that ruminal mucosa of hay-fed sheep had relatively thin stratum corneum formed by two layers of horn cells. Generally, the intake of concentrate diet for various intervals of time resulted in significant highest increase in thickness of stratum corneum. Lakshmishree 
(2014) stated that, the minimum and maximum thickness of stratum corneum in black buck/ buffaloe and in spotted deer/sheep/goat may be directly or could be indirectly correlated with the hay and concentrate-feed, which had thin and thick stratum corneum respectively.

\section{Reticulum:-}

Gross morphology:-

In the present study the primary crest or taller crest were quite big which were divided into smaller crest but were not distinct. The upper border of the taller crest showed pointed projected long conical papillae (Fig.5). Lakshmishree (2014) reported that the reticular crest had two different heights. The taller crest separated the mucosal surface into shallow compartments which were further divided into smaller area with shorter crest. The sides of the crest had vertical recess and mucosa between the crest were covered by conical vertical papillae as reported by Trautmann and Fiebiger (1952), Eurell and Frappier (2006) and Samuelson (2007). Grazing ruminants have higher reticular crests than browsers and have more pronounced secondary, tertiary and even quaternary crests (Hofmann 1969; Hofmann 1973; Langer 1988).

\section{Histology:-}

Pelagalli (2007) observed that in the reticulum of buffalo the muscularis mucosae play an important role in the contraction of reticular cristae and reticular wall. Similarly in the present study such muscularis mucosae was present in the form of a circular cross cut muscular fibres (Fig. 6,7) which help in the formation of a bag helping in the digestion and crushing of food (Ramkrishna and Gadre, 2004). Submucosal plexus in the reticulum indicate intrinsically mucosal function of the reticulum as reported by Yamamoto et al. (1995) in ovine forestomach. The tunica muscularis and tunica serosa did not show any differences as reported by various authors.

\section{Omassum:-}

Gross morphology:-

In the present study the omassal laminae arrangements were similar as reported by various authors. Omassal laminae were studded with small conical papillae. These papillae had conically pointed tips (Fig.8). Lakshmishree (2014) mentioned that the conical papillae were claw shaped in black buck, sheep and goat whereas dome shaped giving wart like appearance in nilgai, spotted deer and buffalo. Which differed from the present study as the conical papillae of the laminae were more pointed conical and did not corroborate with nilgai and buffalo. The relationship between the omassal structure \& function has been a matter of debate. Some authors have suggested that cornified epithelium of the laminae served as a grinding mill while others consider it to allow only small particles of the food to pass on to the lower digestive tract (Bost, 1970). However recently Phillipson (1982) suggested that the omassum was primarily an organ for the absorption of volatile fatty acid, minerals and electrolytes. According to Lakshmishree (2014) black buck and buffalo have been classified under grazer, nilgai and sheep as intermediate and spotted deer as browser.

\section{Histology:-}

In the present study stratum spinosum of the lamina epithelium showed vacuolated cells which are similar to the finding of Aughey and Frye (2010). Lakshmishree (2014) suggested the vacuolated appearance is for the transfer of water and electrolytes and short chain fatty acid. The presence of muscularis mucosae and tunica muscularis in the large omassal laminae (Fig. 9) were similar to that of description given by many others. However, Banks (1993) argued that muscularis mucosae do not arise only from the internal muscle layer. Yamamoto et al. (1995) reported 3 layers of smooth muscle fibres as central intermediate layer and 2 lateral layer without mentioning that the intermediate layer constituted tunica muscularis. Submucosal plexus were reported by Yamanoto et al. (1995). However more such observations have not been made in the present study. El-Gendy and Derbarlah (2010) stated that, omassum may be responsible for the increased absorption of water and nutrients, leafy material ingested by Baladi goats. Pelagalli (2007) reported that peristaltic movement of the omassal musculature squeeze the fluid between the lamina and these fluids were partially absorbed by lamina themselves.

\section{Summary:-}

Finally, in the present study we conclude that based on the gross morphology and histological structures of fore stomach of Wild Gaur, it can be classified under intermediate grazer having both browser and grazer characters. 


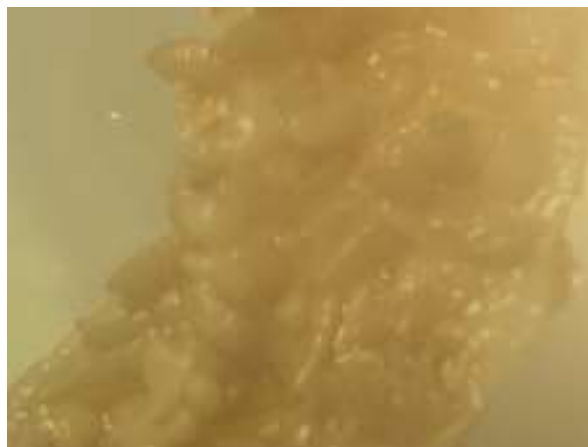

Fig. 1- Photograph showing rumen (under stereo zoom) $10 \mathrm{x}$

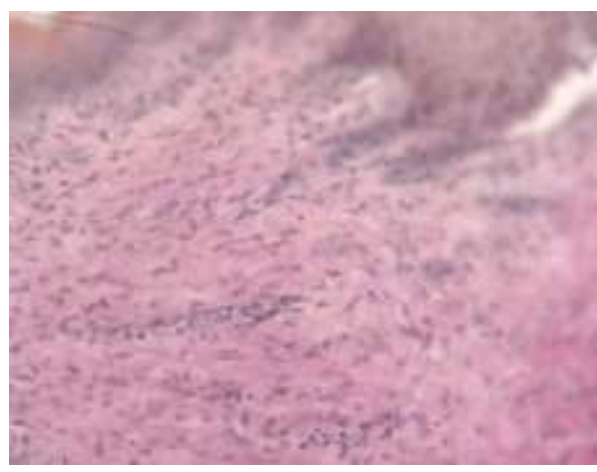

Fig. 3 Photograph showing rumen papilla, $\mathrm{H} \& \mathrm{E} 200 \mathrm{x}$

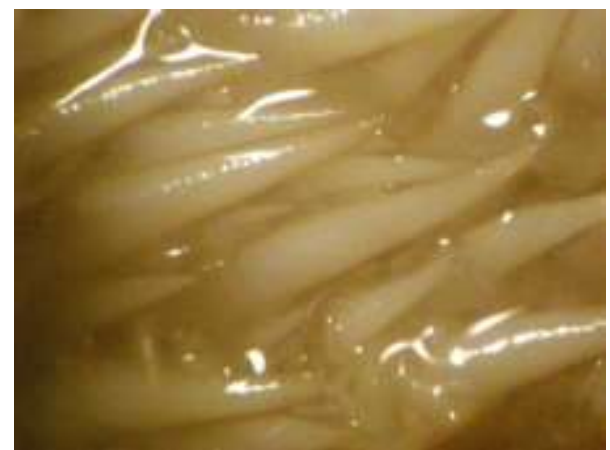

Fig. 5 Photograph showing reticulum (under stereo zoom) 40x

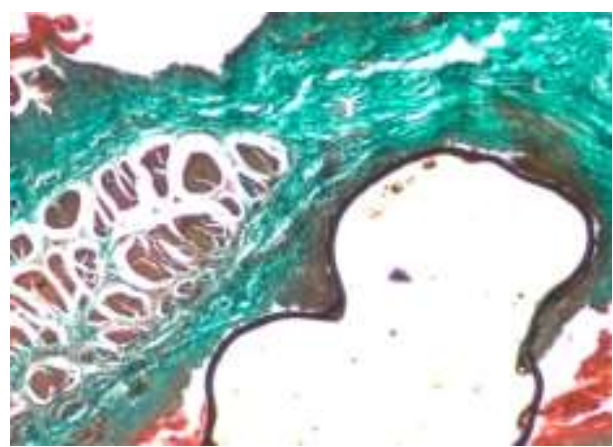

Fig. 7: Photograph showing retculum, trichrome 100x

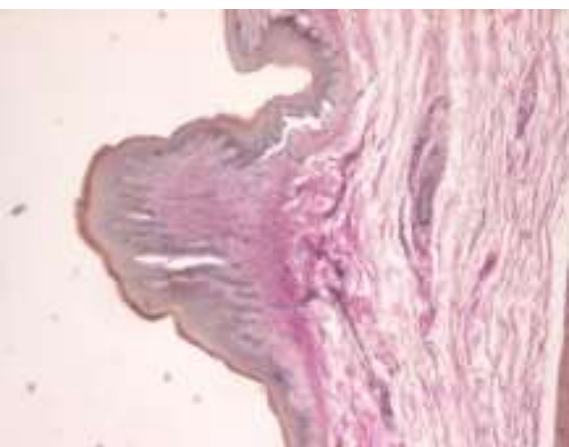

Fig. 2- Photograph showing rumen papilla, $\mathrm{H} \& \mathrm{E} 40 \mathrm{x}$

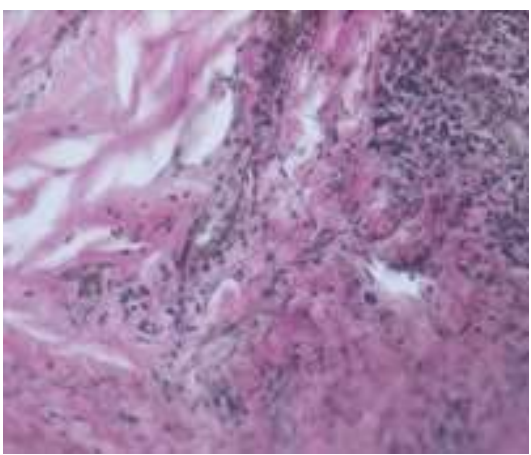

Fig. 4 Photograph showing rumen papilla, $\mathrm{H} \& \mathrm{E} 400 \mathrm{x}$

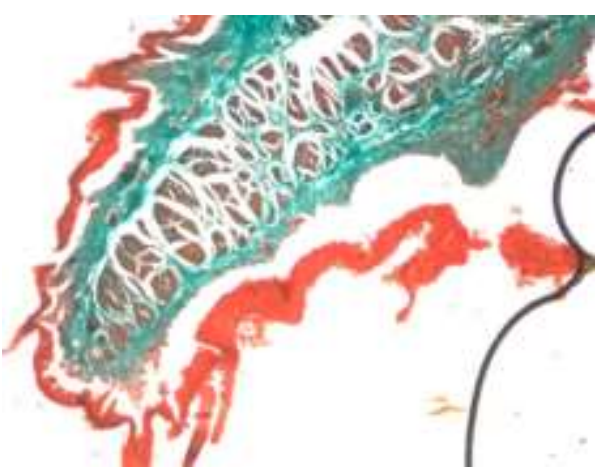

Fig. 6 Photograph showing retculum, trichrome 40x

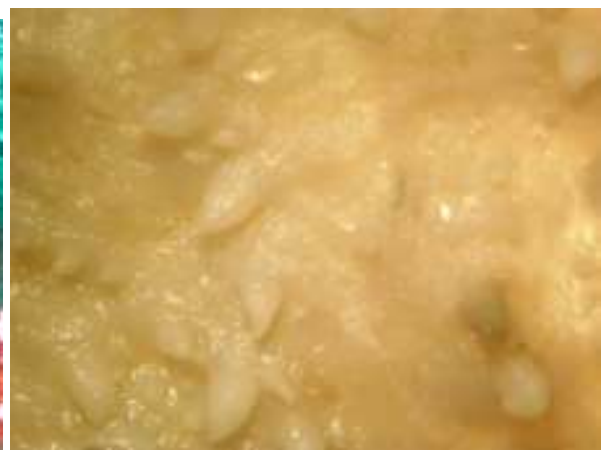

Fig. 8: Photograph showing omassum (under stereo zoom) 10x 


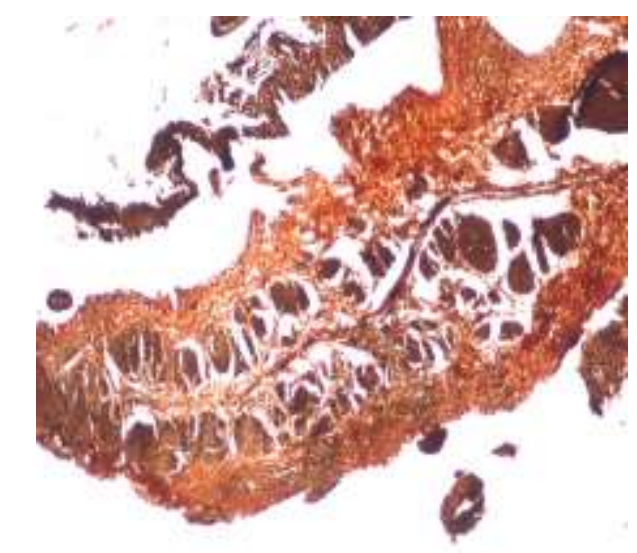

Fig. 9- Photograph showing omassum, reticular stain 200x

\section{References:-}

1. Aughey, E. and Frye, F. L. (2010). Comparative veterinary Histology with linical correlates. Manson publishing, pp:108.

2. Banks, W. J. (1993). Digestive System I Alimentary canal. In: Applied Veterinary Histology. 3rd. Edn. Mosby Year Book (ed). Philadelphia. pp: 326-359.

3. Bost, J. (1970). Omasal physiology. In: Physiology of Digestion and Metabolism in the Ruminant. Phillipson, A.T. (ed). Newcastle upon Tyne: Oriel. pp: 52-56.

4. Bull, L. S., Bush, L. J., Friend, J. D., Harris, J. R. B. and Jones, E. W. (1965). Incidence of ruminal parakeratosis in calves fed different ration and its relation to volatile fatty acid absorption. J. Dairy Sci., 48(11):1459-1466.

5. Clauss, M., Lechner-Doll, M. and Streich, W. J. (2003a). Ruminant diversification as an adaptation to the physicomechanical characteristics of forage: a reevaluation of an old debate and a new hypothesis. Oikos., 102(2):253-262.

6. Dirksen, G., Liebich, H. G., Brosi, G., Hagemeister, H. and Mayer, E. (1984). Morphology of the rumen mucosa and fatty acid absorption in cattle, important factors for health and production. Zentralblatt Fur Veterinarmedizin Reihe., A 31: 414-430.

7. El-Gendy, S. A. A. and Derbalah, A. (2010). Macroscopic and microscopic anatomy of the omasum of the Baladi Goat. J. Appl. Bio. Sci., 4 (3): 37-45.

8. Eurell, J. A. and Frappier, B. L. 2006. Ruminant stomach. In:Dellmann "es text book of V eterinary Histology. Edn. 6th. Blackwell Publishing, pp:189-194.

9. Gabel, G., Martens, H., Suendermann, M. and Galfi, P. (1987). The effect of diet, intraruminal pH and osmolarity on sodium, chloride and magnesium absorption from the temporarily isolated and washed reticulorumen of sheep. Exp Physiol.,72: 501-511.

10. Hofmann, R. R. and Schnorr, B. (1982). The Functional Morphology of the Forestomachs (in German). Ferdinand Enke Verlag, Stuttgart.

11. Hofmann, R. R. and Stewart, D. R. M. (1972). Grazers and Browsers: a classification based on the stomach structure and feeding habits of East African ruminants. Mammalia., 36:226-240.

12. Hofmann, R. R. (1969). Zur Topographie und Morphologie des Wiederkäuermagens im Hinblick auf seine Funktion (nach vergleichenden Untersuchungen an Material ostafrikanischer Wildarten). Zentralblatt für Veterinärmedizin., 10:1-180.

13. Hofmann, R. R. (1973). The ruminant stomach. Stomach structure and feeding habits of East African game ruminants. East African Literature Bureau., 2:1-354.

14. Hofmann, R. R. (1989). Evolutionary steps of ecophysiological adaptation and diversification of ruminants: a comparative view of their digestive system. Oecologia., 78:443.

15. James, E., Nocek, C., Heald, W. and Polan, C. E. (1983). Influence of ration physical form and nitrogen availability on ruminal morphology of growing bull calves. J. Dairy Sci.,67: 334-343.

16. Jones, L., Javed, A. H., Donefer, E. and Gaudreau. (1972). Voluntary intake and nutrient digestibility of forages by goats and sheep. J. Ani. Sci., 34:830.

17. Lakshmishree, K. T. (2014). Gross and histomorphological studies on forestomach of wild ruminants in comparison with domestic ruminants. Ph.D. Thesis submitted to KVAFSU, Bidar, Karnataka. 
18. Langer, P. (1988). The mammalian herbivore stomach. Stuttgart/New York: Gustav Fischer Verlag.

19. Lentle, R. G., Henderson, I. M. and Stafford, K. J. (1996). A multivariate analysis of rumen papillary size in red deer (Cervus elaphus). Can J Zool .,74:2089-2094.

20. Luna, H. T. (1968). Manual of histological staining methods of the Armed forces institute of pathology. Edn.3rd, Mc Graw Hill book company.

21. Pelagalli, G. V. (2007). Morphological studies in the buffalo as a contribution to biotechnological methodologies in the animal production. Ital. J. Anim. Sci., 6(2):184-193.

22. Phillipson, A. T. (1982). Ruminant Digestion. In: M.J. Swenson Duke's Physiology of Domestic Animals. 9th edn. Comstock Publishing Associates. London. pp:27.

23. Ramkrishna, V. and Gadre, K. M. (2004). A systemic histology of domestic animals. Edn. 2nd ., Jaypee Brothers, Medical publishers ltd. pp:10-14.

24. Rasha, S. A. (2007). Diet-dependent morphological changes of the rumen epithelium in sheep. Ph.D. Thesis., Institute of veterinary anatomy, faculty of veterinary medicine free University of Berlin.

25. Samuelson, D. A. (2007). Ruminant stomach. In:Text book of Veterinary Histology. Saunders Elsevier. pp:333335.

26. Shen, Z., Seyfert, H. M., Lohrke, B., Schneider, F., Zitnan, R., Chudy, A., Kuhla, S., Hammon, H. M., Blum, J. W., Martens, H., Hagemeister, H. and Viogt, J. (2004). An energy rich diet causes rumen papillae proliferation associated with more IGF type 1 receptors and increased plasma IGF-1 concentrations in young goats. J. Nutr., 134: 11-17.

27. Trautmann, A. and Fiebiger, J. (1952). The forestomach of the ruminant. In: Fundamentals of the histology of domestic animals. Comstock Publishing Associates. pp: 181-18.

28. Yamamoto, Y., Atoji, Y. and Suzuki, Y. (1995). Morphological study of the submucosal and mucosal plexuses of the sheep forestomach. Ann. Anat., 177(5): 405-412. 